AFMRD Form the asscation Association of Family Medicine of Family Medicine Residency Directors Residency Directors

Ann Fam Med 2018;16:370. https://doi.org/10.1370/afm.2274.

\section{JOYS OF BEING A PROGRAM DIRECTOR}

The role of a Program Director often involves handling multiple tasks on a daily basis. I recently had a particularly difficult week. First, I was notified that my 4 -year-old program only filled 3 out of 6 positions in the Match. All I really knew about the SOAP was that I never wanted to go through the process. So, I spent the better part of the week making phone calls to potential candidates while wondering what went wrong with our interview and selection process. We were fortunate to acquire 3 quality resident candidates. I was still reeling from an administrative hearing the previous week. The hearing had overturned my decision not to renew one of my resident's contracts. As I was working on this issue, 1 of my full-time faculty members told me of her decision to leave our program in order to accept a position at the medical school. With little advance notice, I was going to be left with only 2.5 faculty FTEs for 18 residents. Finally, to cap off my week, I was asked to fill in as interim Family Medicine Department Chair. As I sat in my office trying to finish up the work for the week on Friday afternoon, I couldn't help but reflect on the fact that this was not a job that I had signed up for. I was overwhelmed, exhausted, and looking forward to the weekend.

As I was shutting off my computer and turning off the office lights, there was a soft knock on my door. Certainly there wouldn't be another challenge to deal with at 4:30 on Friday afternoon! The door opened slowly and there stood one of my second-year residents. Something was obviously wrong. Normally she was so dynamic and full of energy, but she just stood in the doorframe with her head down asking if we could talk. A multitude of thoughts started running through my mind. Had she had an issue with an attending or residents on another service? Had she been reprimanded by the program coordinator for not having logged her duty hours? Did she want to discuss a particularly perplexing patient? I invited her to sit down. Initially she said very little. I remained quiet and noticed tears running down her cheeks. Through those tears she began to tell me that just hours earlier a close family member had been admitted to the ICU with a hemorrhagic stroke. She asked vague medical questions. What could be the etiology of a hemorrhagic stroke in someone so young? What was the evidence-based treatment for such a condition? Realistically, what was the mortality of such a patient who was already ventilator dependent in an ICU? I did my best to answer her questions with sensitivity. But with each ensuing answer I had the impression that her medical questions were not the motivation for her visit to my office. My resident simply needed to talk with someone with whom she felt safe, and with whom she had built a relationship of trust. The medical questions didn't matter. She was hurting and she wanted to be heard, understood, and validated. I forgot about the hour and the looming weekend. We talked not about medicine but about relationships; not about probabilities and morbidities but rather about spirituality. An hour later my resident left the office. Although she left in better spirits, our conversation did not change the reality that her loved one would die within 24 hours. She did, however, appreciate the time taken to listen and to understand. That had made all the difference. As I got in my car to drive home, I reflected on the many demands of being a Program Director such as the ACGME, the affiliate teaching hospital, our continuity clinic, patient numbers, the resident match, the never ending reporting, keeping faculty happy and productive, and the increasing demands of a newly opened medical school. I hadn't even left the parking lot when I realized the reason we love this job is the residents. To be able to provide a safe, inviting, understanding environment in which new physicians can spread their fledgling wings and find their own way in an increasingly complex and demanding road of medical education and patient care is really the joy of being a Program Director.

So as we near the end of another academic year, begin preparing for our graduations and welcoming our new interns, let's not forget why we are Program Directors. In the midst of all that we do, we serve as the compass for our respective programs to keep focused on the goal we all share-the training and mentoring of the next generation of Family Medicine Physicians. We have the honor and privilege to serve an integral role and in the midst of all the chaos, we need to remain focused on why we do what we do and the joy that it brings.

Curtis L. Galke, DO, FAAFP, Sherri L. Morgan, MD, MPH, FAAFP 